\title{
Aislamiento y caracterización de las células madre mesenquimales derivadas de líquido sinovial de caballo que presentan el marcador de superficie STRO-1
}

\author{
Isolation and characterization of mesenchymal stem cells derived from horse \\ synovial liquid presenting the STRO-1 surface marker
}

\author{
Hugo Gonzales Figueroa ${ }^{1,3}$, Yat Sen Wong', Hugo Mauricio Gonzales Molfino', \\ José Luis Llanos Carrillo ${ }^{1}$
}

\section{Resumen}

\begin{abstract}
Se analizaron las propiedades biológicas de las células madre mesenquimales (CMM) provenientes del líquido sinovial de las articulaciones de las extremidades de caballo. Las muestras fueron caracterizadas por su peculiaridad de adherirse al plástico de los frascos de cultivos. Se utilizó la técnica de campos electromagnéticos (MACS) y el biomarcador de superficie STRO-1 con la finalidad de optimizar su aislamiento mediante el enriquecimiento de células precursoras mesenquimales (CMM-LS). Para determinar la expresión de los genes multipotencia, se extrajo el ARN total y se usó la transcriptasa reversa M-MLV para el ADNc, el que sirvió como molde para la qPCR (PCR cuantitativa). El qPCR se realizó utilizando el sistema BioRad con cuantificación mediante Sybr Green. Los genes de multipotencia cuantificados fueron OCT4 y NANOG. Las células seleccionadas utilizando MACS con el biomarcador de superficie STRO-1 (CMM-LS STRO-1),
\end{abstract}

\footnotetext{
${ }^{1}$ Laboratorio de Biotecnología Animal, Facultad de Ciencias Biológicas, Universidad Ricardo Palma, Lima, Perú

${ }^{2}$ Facultad de Ciencias Veterinarias, Universidad de Concepción, Chile

${ }^{3}$ E-mail: hgonzalesfigueroa@urp.edu.pe
}

Recibido: 2 de marzo de 2021

Aceptado para publicación: $x x x$

Publicado: 22 de diciembre de 2021

CLos autores. Este artículo es publicado por la Rev Inv Vet Perú de la Facultad de Medicina Veterinaria, Universidad Nacional Mayor de San Marcos. Este es un artículo de acceso abierto, distribuido bajo los términos de la licencia Creative Commons Atribución 4.0 Internacional (CC BY 4.0) [https:// creativecommons.org/licenses/by/4.0/deed.es] que permite el uso, distribución y reproducción en cualquier medio, siempre que la obra original sea debidamente citada de su fuente original 
proliferan más rápidamente que las CMM-LS obtenidas sin purificar. Además, manifestaron una mayor predisposición a diferenciarse en condrocitos y osteocitos en comparación a las CMM-LS sin purificar, y una menor predisposición a diferenciarse en adipocitos. Así mismo, la expresión de OCT-4 fue significativamente superior en la CMM-LS STRO1 en comparación con las CMM-LS sin purificar. La expresión de NANOG fue ligeramente superior en las CMM-LS STRO-1, pero sin diferencia significativa. Los resultados hacen suponer que la coexpresión de OCT-4 y Nanog podrían incrementar las funciones fisiológicas de las CMM-LS STRO-1 relacionadas con una mejor proliferación, autorrenovación y la predisposición a diferenciarse en los linajes osteocondrales; sin embargo, se necesita aclarar el papel funcional de estos marcadores de pluripotencia en células madre adultas.

Palabras clave: células madre mesenquimales, CMM, líquido sinovial de caballos, biomarcador, STRO-1, OCT4, NANOG

\section{Abstract}

The biological properties of mesenchymal stem cells (MSCs) from synovial fluid from horse limb joints were analysed. The samples were characterized by their peculiarity of adhering to the plastic of the culture flasks. The electromagnetic field technique (MACS) and the surface biomarker STRO-1 were used to optimize their isolation by enriching mesenchymal precursor cells (MSC-LS). To determine the expression of multipotency genes, total RNA was extracted and M-MLV reverse transcriptase was used for the cDNA, which served as a template for qPCR (quantitative PCR). qPCR was performed using the BioRad system with Sybr Green quantification. The multipotency genes quantified were OCT4 and NANOG. The cells selected using MACS with the surface biomarker STRO-1 (CMM-LS STRO-1) proliferate more rapidly than the CMM-LS obtained without purification. In addition, they showed a greater predisposition to differentiate into chondrocytes and osteocytes compared to non-purified LS-MSCs, and a lower predisposition to differentiate into adipocytes. Likewise, the expression of OCT-4 was significantly higher in the CMM-LS STRO-1 compared to the non-purified CMM-LS. NANOG expression was slightly higher in STRO-1 CMM-LS, but without significant differences. The results suggest that the co-expression of OCT-4 and Nanog could increase the physiological functions of MSC-LS STRO-1 related to better proliferation, self-renewal, and the predisposition to differentiate in osteochondral lineages; however, the functional role of these pluripotency markers in adult stem cells needs to be clarified.

Key words: mesenchymal stem cells, MSC, horse synovial fluid, biomarker, STRO-1, OCT4, NANOG

\section{INTRODUCCIÓN}

Las células madre mesenquimales (CMM) son células adultas multipotentes que se obtienen de fuentes conocidas como médula ósea, tejido conectivo y sangre del cor- dón umbilical, entre otras, con plasticidad para diferenciarse en linajes celulares de condrocitos, adipocitos y osteocitos y de las que se han logrado establecer cultivos que ha permitido estudiar sus propiedades biológicas (Carvalho et al., 2013). 
Una fuente alternativa y promisoria para la obtención de CMM equinas son los tejidos sinoviales, por lo que es importante conocer sus características fenotípicas y potencial de diferenciación. Se ha reportado que las células mesenquimales cultivadas provenientes del líquido sinovial (CMM-LS) y de la membrana sinovial (CMM-MS) de articulaciones de caballos sanos, con osteoartritis o con osteocondritis disecante presentaron morfología fibroblastoide y capacidad de adherirse al plástico, así como expresión positiva a los marcadores de multipotencia como CD90 y CD44 (Hernández et al., 2011), además de marcadores de sinoviocitos como lisozima, PGP 9.5, PCNA y vimentina (Zayed et al., 2017). Estas células fueron capaces de diferenciarse en linajes condrogénicos, osteogénicos y, aunque pobremente, en linajes adipogénicos (Fülber et al., 2016).

Se ha demostrado que las células mesenquimales aisladas del líquido sinovial de caballos son fuertemente positivas para CD44, CD90 y el complejo mayor de histocompatibilidad (MHC) de clase I, así como moderadamente positivas para CD11a/CD18, CD105 y MHC de clase II y negativas para CD34 y CD45. Estas células derivadas del líquido sinovial se diferencian en linajes condrogénicos, osteogénicos, adipogénicos y tenogénicos (Murata et al., 2014). Al comparar el potencial condrogénico in vitro de poblaciones de células madre mesenquimales procedentes de médula ósea equina (CMMMO) y CMM-LS del mismo donante equino, se encontró que eran similares en morfología celular, viabilidad e inmunofenotipo, pero varían en su potencial condrogénico y en la expresión de las proteínas condrogénicas (Zayed et al., 2017). Resultados similares muestran que las CMM derivadas de la membrana sinovial tienen mayor potencial de regeneración articular y capacidad de diferenciación condrogénica, ya que son una fuente más cercana a los condrocitos (Santos et al., 2018). A diferencia de las CMM derivadas de la médula ósea que expresan marcadores de hipertrofia y osteogénesis (Runx2) cuando son diferenciadas a condrocitos, las del líquido sinovial producen una mayor cantidad de tejido cartilaginoso y no expresan un fenotipo hipertrófico (Chen et al., 2016).

Las CMM se pueden aislar de tejidos usando otros marcadores de multipotencial como STRO-1, proteína de superficie celular, y CD 146, molécula de superficie celular perteneciente a la superfamilia de las inmunoglobulinas, expresada en células provenientes del ligamento periodontal humano (Xu et al., 2009).

En relación al aislamiento y purificación de CMM, se viene usando con éxito la técnica de clasificación de células activadas magnéticamente (MACS) que evita la heterogeneidad celular y permite tener un linaje celular puro en las placas de cultivo (Chen et al., 2016). Esta técnica consiste en utilizar partículas magnéticas unidas a anticuerpos para marcar las células que expresan el fenotipo que se desea aislar y ser separadas posteriormente a través de un campo magnético (Korkusuz et al., 2018).

Esta investigación tuvo como objetivo purificar las CMM provenientes del fluido sinovial de las articulaciones de caballos que expresan el marcador de superficie STRO-1 utilizando la técnica de MACS con la finalidad de evaluar su capacidad de proliferación y capacidad multipotente, así como los linajes celulares en que pueden diferenciarse.

\section{Materiales Y MéTodos}

\section{Muestras}

Las muestras se obtuvieron de tres Caballo Peruano de Paso en aparente buen estado de salud, que fueron sacrificados en el matadero local Casa Blanca, localizado en el distrito de Pachacámac, Lima, Perú. 


\section{Células Madre Mesenquimales de Lí- quido Sinovial (CMM-LS)}

El líquido sinovial (LS) se obtuvo por aspiración directa, usando una jeringa estéril de calibre 20, del metatarso, previamente afeitadas y desinfectadas con alcohol al 70\% seguido de solución yodada $(10 \%$ en solución salina). Se diluyeron aproximadamente $2 \mathrm{ml}$ de LS en PBS (buffer fosfato) suplementado con $400 \mathrm{U} / \mathrm{ml}$ de penicilina, $400 \mathrm{U} /$ $\mathrm{ml}$ de estreptomicina y $1 \mu \mathrm{g} / \mathrm{ml}$ de anfotericina B. Las muestras se centrifugaron a $185 \mathrm{~g}$ durante 10 minutos a temperatura ambiente. El botón celular se suspendió en medio DMEM con alto contenido en glucosa suplementado con $10 \%$ de suero fetal bovino y $100 \mathrm{U} / \mathrm{ml}$ de penicilina, $100 \mathrm{U} / \mathrm{ml} \mathrm{de}$ estreptomicina y $0.25 \mu \mathrm{g} / \mathrm{ml}$ de anfotericina $\mathrm{B}$ (medio de cultivo con solución antibióticaantimicótica 1x). Las células posteriormente fueron cultivadas en placas de Petri de 30 $\mathrm{mm}^{2}$ a $38{ }^{\circ} \mathrm{C}$ en $5 \%$ de $\mathrm{CO}_{2}$.

Cuando las células alcanzaron un 8090\% de confluencia se realizó el primer pasaje. Las células se cosecharon con tripsinaEDTA al $0.05 \%$ y fueron sembradas en una placa de Petri de $100 \mathrm{~mm}^{2}$. Finalmente, luego del tercer pasaje, los cultivos primarios resultantes se criopreservaron con medio de cultivo suplementado al $10 \%$ de DMSO (dimetil sulfóxido) y fueron almacenados en nitrógeno líquido hasta el inicio de los procedimientos experimentales.

\section{Purificación del CMM-LS STRO-1}

La purificación de CMM-LS STRO-1 se realizó mediante la técnica de clasificación de células activadas magnéticamente (MACS), siguiendo las instrucciones del proveedor (Miltenyi Biotec, Alemania). En resumen, las células se cosecharon con tripsinaEDTA al $0.05 \%$, fueron suspendidas en PBS con $0.5 \%$ de albúmina y se adicionó una solución con anticuerpos de ratón anti STRO-1 conjugadas con FITC (10 ìg/ml). La mezcla fue incubada durante $1 \mathrm{~h}$ a $4{ }^{\circ} \mathrm{C}$, las células fueron lavadas dos veces y posteriormente incubadas en presencia de microesferas conjugadas con anticuerpos anti FITC durante 30 min en oscuridad a $4{ }^{\circ} \mathrm{C}$. Seguidamente, las células fueron lavadas dos veces para eliminar el exceso de anticuerpos y finalmente se pasaron por un campo magnético. Las células retenidas en la columna se liberaron y diluyeron en PBS con albúmina al $0.5 \%$, luego se centrifugaron a $289 \mathrm{~g}$ y se suspendieron en medio de cultivo (CM) y cultivadas hasta alcanzar la semi confluencia, para después ser criopreservadas en nitrógenolíquido.

\section{Proliferación Celular}

Las células se sembraron en placas de 12 pocillos a 30000 células por pocillo en $\mathrm{CM}$ a $38^{\circ} \mathrm{C}$ durante seis días sin reemplazo de medio. Luego se contó nuevamente el número de células y se calculó el tiempo de duplicación de la población, utilizando la herramienta en línea gratuita (http://www.protocol-online.org/biology-forums-2/posts/ 13968.html). Todo el recuento se realizó utilizando la cámara Neubauer. Las células se lavaron dos veces con PBS y se cosecharon con Tripsina-EDTA. Las células resultantes se resuspendieron en $1 \mathrm{ml}$ de formalina al $4 \%$ y se diluyeron en PBS 1:100.

\section{Diferenciación a Tres Linajes Celulares}

Las células se sembraron en placas a 300000 células por pocillo en 12 pocillos en CM. Al alcanzar el 95\% de confluencia se cultivó en medio de diferenciación específica durante 21 días.

- Para la diferenciación osteogénica, el medio DMEM con alto contenido de glucosa fue suplementado con $10 \%$ de suero fetal bovino, dexametasona $0.1 \mu \mathrm{M}$, âglicerofosfato $10 \mathrm{mM}$, sal trisódica del ácido L-ascórbico 2-fosfato $50 \mu \mathrm{M}, \mathrm{y} 1 \mathrm{x}$ de solución antibiótica-antimicótica.

- Para la tinción osteogénica específica se usó rojo de Alizarina para detectar la deposición extracelular de calcio. La monocapa se fijó usando una solución de formalina al $10 \%$ durante 1 hora, se lavó 3 veces con agua corriente y se añadió 
$1 \mathrm{ml}$ de solución de rojo de alizarina al $2 \%$ en cada pocillo durante $1 \mathrm{~h}$. Luego se eliminó el sobrante y los pocillos se lavaron 6 veces con agua de grifo hasta que el agua se mantuvo clara. Seguidamente, los pocillos se llenaron con glicerina y se mantuvieron a temperatura ambiente.

- Para la diferenciación condrogénica, el medio consistió en DMEM con alto contenido de glucosa suplementado con suero fetal bovino al $10 \%, 10 \mathrm{ng} / \mathrm{ml}$ de TGFâ $3,10 \mathrm{~g} / \mathrm{ml}$ de insulina, sal trisódica del ácido L-ascórbico 2-fosfato y $1 \mathrm{x}$ de solución antibiótico-antimicótica.

- Para la detección condrogénica, se usó una solución de azul alcián al $0.02 \%, \mathrm{pH}$ 1. Después de la fijación de la monocapa con etanol al $100 \%$ durante $1 \mathrm{~h}$, se añadió $1 \mathrm{ml}$ de la solución durante 3 horas, después de este periodo las monocapas se enjuagaron 6 veces con etanol al $100 \%$ y se cubrieron con glicerina.

- Para la diferenciación adipogénica se utilizó DMEM con alto contenido de glucosa suplementado con suero fetal de bovino al $10 \%, 1 \mu \mathrm{M}$, insulina $10 \mu \mathrm{g} / \mathrm{ml}$, 3 -isobutil-1-metilxantina $0.5 \mathrm{mM}$, indometacina $0.1 \mathrm{mM}$ y $1 \mathrm{x}$ de solución antibiótica-antimicótica.

- La tinción Oil Red se usó para la detección adipogénica. Las monocapas se lavaron 3 veces con PBS y se fijaron con $10 \%$ de formaldehído durante $1 \mathrm{~h}$, luego se tiñeron con $2 \%$ de Oil Red durante 1 $\mathrm{h}$ con agitación suave. Se eliminó el exceso de tinción y la monocapa se lavó 5 veces con agua del grifo.

Para medir la diferenciación, se utilizó el software de imagen J. Se seleccionaron y fotografiaron cinco campos representativos de cada muestra. Los valores de diferenciación se expresaron como porcentaje del área cubierta por cada tinción específica.

\section{Expresión de Genes Multipotencia}

El ARN total se extrajo usando Trizol. La síntesis de ADNc se preparó usando la transcriptasa reversa M-MLV y el ADNc resultante se usó como molde para la qPCR (PCR cuantitativa). El qPCR se realizó utilizando el sistema BioRad con cuantificación mediante Sybr Green. Los genes de multipotencia cuantificados fueron OCT4 y NANOG. El gen utilizado para normalizar la expresión génica fue GAPDH y la cuantificación relativa de los genes objetivo se realizó con el método delta delta $\mathrm{Ct}\left(2^{-\mathrm{AäCT}}\right)$.

\section{Análisis Estadístico}

Los resultados para cada ensayo fueron expresados como la media aritmética con su respectiva desviación estándar. Las diferencias estadísticas significativas se calcularon usando la prueba t-Student para muestras dependientes con un valor de $\mathrm{p}<0.05$ usando GraphPad Prism Software v. 8.3.1.

\section{Resultados}

\section{Aislamiento y Enriquecimiento Magné- tico}

Las CMM aisladas de líquido sinovial sin purificar (CMM-LS) de las articulaciones de caballo mostraron capacidad de adherirse al plástico y mostraron morfología fibroblastoide cuando fueron observadas en el tercer pasaje. De la misma manera, cuando se usó la técnica de clasificación de células activadas magnéticamente (MACS), se logró purificar las CMM de líquido sinovial que expresaban el marcador STRO-1 (CMMLS STRO-1); sin embargo, no mostraron diferencias morfológicas aparentes en comparación a las CMM-LS (Figura 1). 

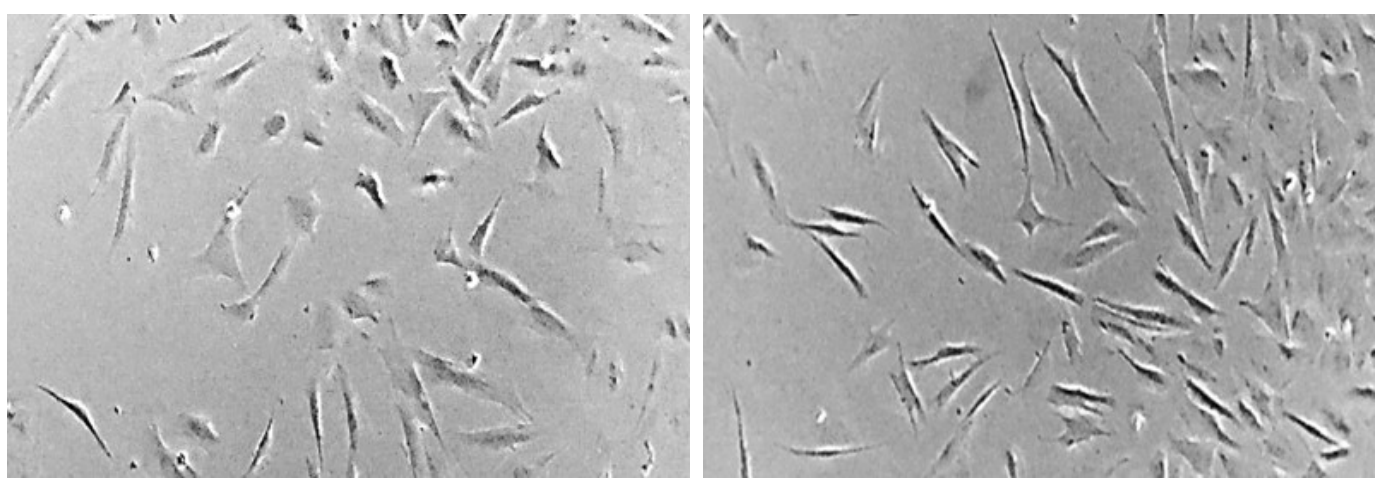

Figura 1. Morfología de las células madre mesenquimales (CMM). Izquierda: CMM-LS. 40X; Derecha: CMM-LS STRO-1·40X

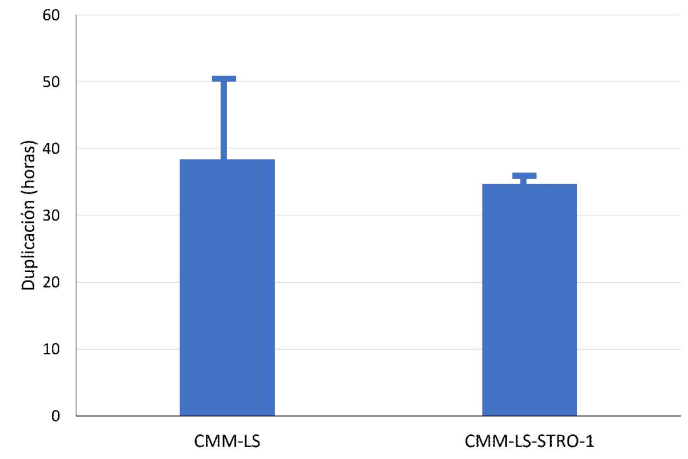

Figura 2. Tiempo de duplicación de las células madre mesenquimales (CMM) $(\mathrm{p}>0.05)$

\section{Proliferación Celular}

El tiempo de duplicación de las CMMLS fue de $38.42 \pm 12.05 \mathrm{~h}$ y de las CMM-LS STRO-1 de $34.7 \pm 1.54 \mathrm{~h}$. Las CMM-LS STRO-1 muestran una ligera reducción del tiempo de duplicación en $4 \mathrm{~h}$ aproximadamente, pero sin diferencias significativas entre los tipos celulares (Figura 2).

\section{Diferenciación Celular}

Después de 21 días de inducción a los tres linajes celulares (adipocitos, condrocitos y osteocitos), las CMM-LS y las CMM-LS STRO-1 fueron capaces de diferenciarse en los tres linajes celulares. La diferenciación adipogénica mostró la presencia de pequeñas vesículas lipídicas que fueron positivas a la tinción Oil Red (Figura 3A,B). Las CMMLS mostraron un área de diferenciación adipogénica significativamente mayor (31.44 $\pm 4.16 \%$ ) con respecto a las CMM-LS STRO-1 (17.33 $\pm 3.09 \%)$, que se relacionó con el tamaño de sus vesículas (Figura 3C).

Durante la diferenciación condrogénica se evidenció la secreción de glucosaminoglicanos (GAG) que fueron detectados con azul de alcian. La comparación del área de diferenciación condrogénica entre las CMM-LS y CMM-LS STRO-1 no se pudo analizar debido a que estas últimas formaron una micromasa gelatinosa (Figura 4B). Esta cualidad denota cambios en la morfología y arquitectura de la población celular que está asociada a una mayor secreción y deposición de proteínas de la matriz extracelular, 

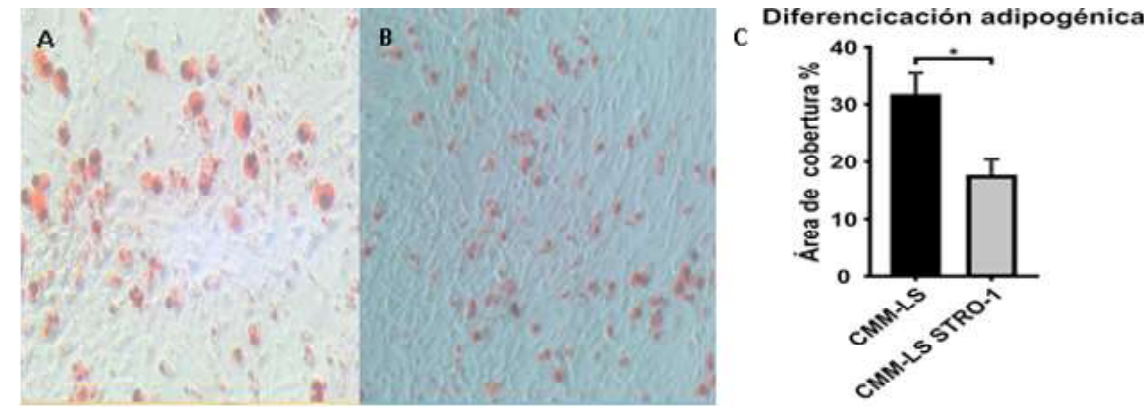

Figura 3. Diferenciación adipogénica. (A) Diferenciación adiposa de CMM-LS. (B) Diferenciación adiposa de CMM-LS STRO-1. (C) Área de cobertura de la diferenciación adipogénica. $(\mathrm{p}<0.05)$

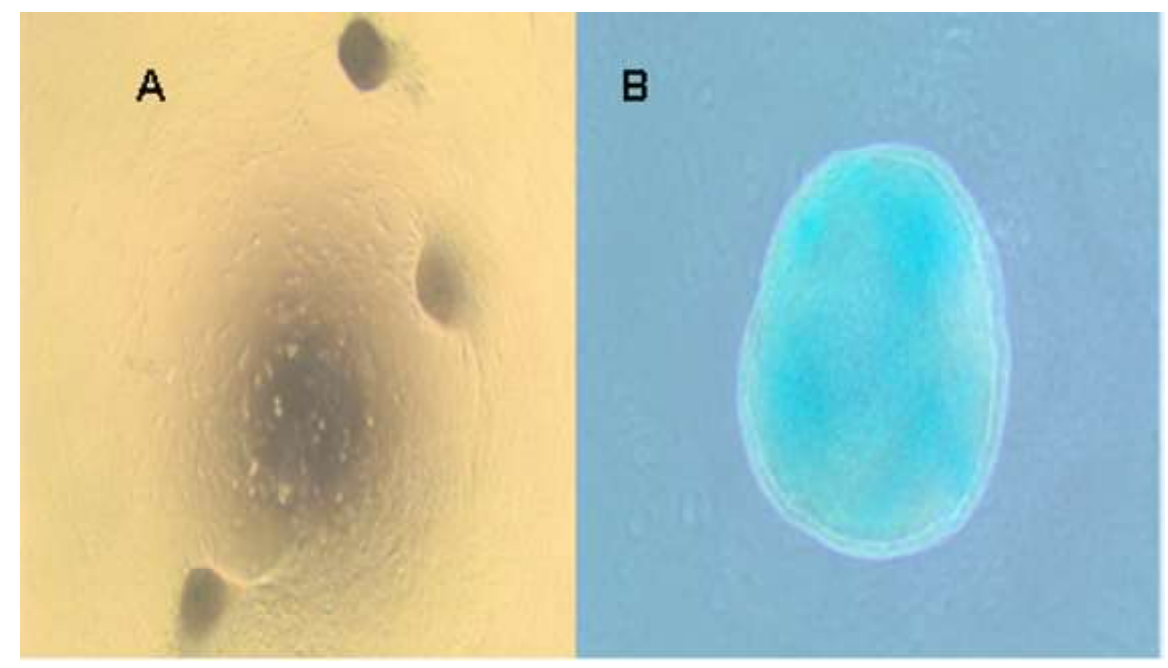

Figura 4. Diferenciación condrogénica. (A) Diferenciación condrogénica incompleta de CMMLS. (B) Diferenciación condrogénica CMM-LS STRO-1 con formación de micromasa

siendo esta característica un indicador de una mejor capacidad condrogénica en comparación a las CMM-LS que tuvieron una condrogénesis incompleta, mostrando nódulos aislado de diferenciación (Figura 4A).

Las células que fueron inducidas a diferenciación osteogénica sintetizaron una matriz extracelular rica en cristales de hidroxiapatita de calcio que fueron teñidas positivamente con rojo de alizarina (Figura
5A,B). Las CMM-LS STRO-1 mostraron un área de diferenciación adipogénica significativamente mayor $(64.44 \pm 40 \%)$ con respecto a las CMM-LS (50.67 $\pm 5.50 \%$, Figura $5 \mathrm{C})$.

\section{Expresión de Genes Multipotencia}

La expresión del factor de transcripción OCT4 muestra un incremento significativo en CMM-LS STRO-1 en comparación a las CMM-LS. La diferencia en el nivel de ex- 

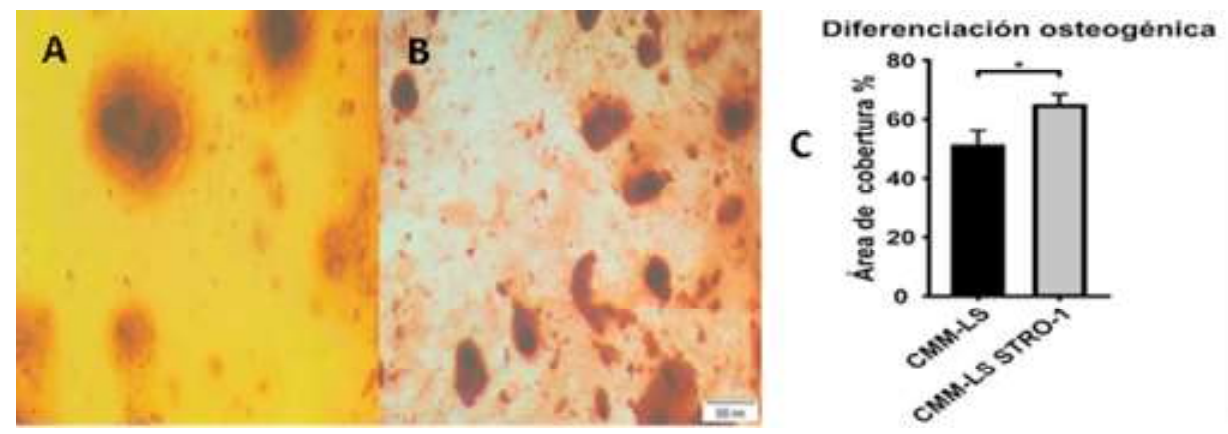

Figura 5. Diferenciación osteogénica. Diferenciación osteogénica de CMM-LS; (B) Diferenciación osteogénica CMM-LS STRO-1 que muestra una deposición mineral masiva; (C) Área de cobertura de la diferenciación osteogénica $(\mathrm{p}<0.05)$
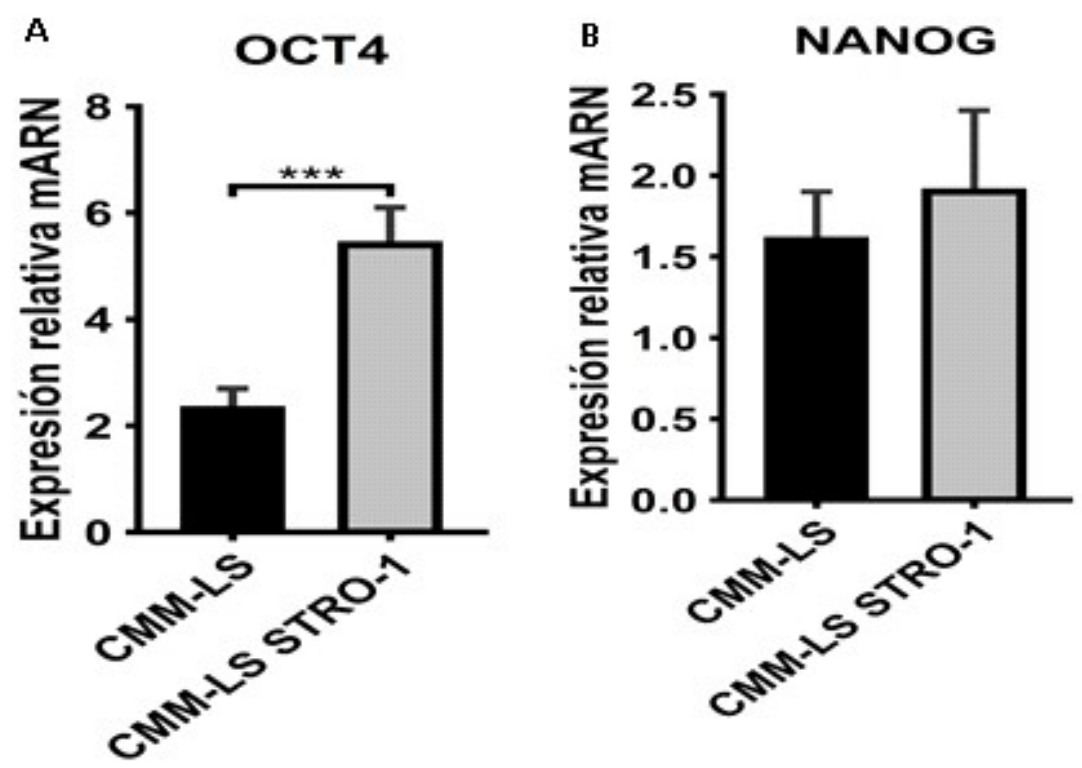

Figura 6. Expresión relativa de genes de multipotencia. (A) Expresión relativa de OCT4 en CMM-LS y CMM-LS STRO1 ( $<<0.01)$; (B) Expresión relativa de OCT4 en CMMLS y CMM-LS STRO1 $(\mathrm{p}<0.01)$

presión relativa fue de aproximadamente cuatro unidades arbitrarias (Figura 6A). Por otro lado, NANOG, otro factor transcripcional de multipotencia, mantuvo una expresión relativa similar entre las CMM-LS y las CMMLS-STRO-1 (Figura 6B). Este resultado sugiere que existe una correlación entre las células que expresan el marcador STRO-1 y la expresión de OCT4.

\section{Discusión}

Se analizaron las propiedades biológicas de las células madre mesenquimales provenientes del líquido sinovial de las articulaciones de las extremidades de caballo (CMMLS). Las muestras obtenidas fueron caracterizadas por su peculiaridad de adherirse al 
plástico de los frascos de cultivos, indicador usado también para CMM provenientes de médula ósea (Tondreau et al., 2004) de tejido adiposo (Estrada y Venegas, 2007) y de pulpa dentaria (Takeyasu et al., 2006), entre otras. Se observó que estas células de forma fibroblastoide crecían como focos de células denominadas, según Friedenstein et al. (1976), unidades de fibroblastos formadoras de colonias, que mantienen su morfología por periodos de cultivo relativamente prolongados, lo que ocurre de la misma manera en cultivos de CMM de origen adiposo (Estrada y Venegas, 2007).

Existen distintos mecanismos de separación de células que permiten organizarlas acorde con ciertas características morfológicas, de manera que se pueda hacer una selección específica con la finalidad de optimizar su aislamiento mediante el enriquecimiento de células precursoras mesenquimales (CMM) con mayor pureza con un biomarcador determinado. Las CMM cardiovasculares humanas obtenidas mediante inmunoselección para el antígeno precursor del estroma 1 (STRO-1) tienen una mayor clonogenicidad, capacidad proliferativa, potencial de diferenciación multilinaje y expresión de ARNm con relación a las obtenidas por el método tradicional (Psaltis et al., 2010). Los resultados presentados utilizando la técnica de campos electromagnéticos con el biomarcador de superficie STRO-1 (CMM-LS STRO-1) tienen la capacidad de proliferar más rápidamente que las CMMLS obtenidas sin purificar. Además, manifestaron una mayor predisposición a ser diferenciadas a condrocitos y osteocitos en comparación con las CMM-LS sin purificar, y una menor predisposición a diferenciarse en adipocitos. Esta predisposición hacia los linajes osteocondrales se debería a que las células que expresan STRO-1 tienen el potencial de formar nuevo cartílago de forma espontánea (Otsuki et al., 2009) y, además, porque los condrocitos del tejido hialino del cartílago articular surgen de las CMM (Vinod et al., 2018). Esta capacidad de las CMM-LS STRO-1 se manifiesta en muestras huma- nas, diferenciándose en adipocitos, condrocitos y osteocitos (Koyama et al., 2011) Como se puede apreciar las CMM aisladas mediante STRO-1 / (MACS) muestran una tendencia significativa a diferenciarse como linajes osteocondrales.

En las CMM el aumento de su potencial de proliferación y diferenciación está en estrecha relación con la expresión de los factores de transcripción OCT-4 y Nanog, regulando positivamente la ADN (citosina-5) metiltransferasa (DNMT-1) codificada en humanos por el gen DNMT-1, importante en el mantenimiento de autorenovación y el estado indiferenciado (Tsai et al., 2012). Es por esto que se utilizan como marcadores para determinar si una célula es pluripotente, ya que, como se ha indicado, están involucrados en la supresión de genes de diferenciación. Resultados similares usando los mismos marcadores de toti y multipotencia han sido reportados por Prado et al. (2015), sugiriendo que tanto el líquido como la membrana sinovial de equinos parecen ser una fuente de células madre con potencial de pluripotencia.

Estos resul tados hacen suponer que la coexpresión de OCT-4 y Nanog podrían incrementar las funciones fisiológicas de las CMM-LS STRO-1 relacionadas con una mejor proliferación, autorrenovación y la predisposición a diferenciarse a los linajes osteocondrales; sin embargo, se necesitan real izar estudios que permitan aclarar el papel funcional de estos marcadores de pluripotenciaen célul as madreadultas. Como aplicación inmediata, los resultados obtenidos podrían constituir una opción atractiva para el tratamiento delesiones articulares queson comunes en cabal los de al to rendimi ento.

\section{Conclusiones}

- Las células madre derivadas del líquido sinovial son de naturaleza mesenquimal, porque expresan los marcadores específicos que permiten identificar su inmunofenotipo. 
- Las células madre mesenquimales de fluido sinovial positivas a STRO-1 pueden ser fácilmente aisladas utilizando la técnica de MACS.

- La coexpresión de OCT4 y NANOG en las CMM-LS STRO-1 podría estar relacionada con sus propiedades fisiológicas.

- Las de CMM-LS STRO-1 presentan propiedades biológicas que pueden mejorar la regeneración osteocondral en las articulaciones de caballo.

\section{Literatura Citada}

1. Carvalho AM, Yamada ALM, Golim MA, Alvarez LEC, Jorge LL, Conceiçãa ML, et al. 2013. Characterization of mesenchymal stem cells derived from equine adipose tissue. Arq Bras Med Vet Zoo 65: 939-945. doi: 10.1590/S0102-09352013000400001

2. Chen Y, Bianchessi M, Pondenis H, Stewart M. 2016. Phenotypic characterization of equine synovial fluid-derived chondroprogenitor cells. Stem Cell Biol Res 3: 1-10. doi: 10.7243/2054-717x-3-1

3. Estrada R, Venegas P. 2007. Comparación de diferentes protocolos para el cultivo de células madre mesenquimales de origen adiposo. Rev Costarric Cienc Med 28: 21-28.

4. Friedenstein A, Gorskaja F, Kulagina N. 1976. Fibroblast precursors in normal and irradiated mouse hematopoietic organs. Exp Hematol 4: 267-274.

5. Fülber J, Maria DA, da Silva LC, Massoco CO, Agreste F, Baccarin RY. 2016. Comparative study of equine mesenchymal stem cells from healthy and injured synovial tissues: An in vitro assessment. Stem Cell Res Ther 7: 35 . doi: 10.1186/s13287-016-0294-3

6. Hernández G, Mora F, Rodriguez L, Ramírez R. 2011. Etiología, patogénesis, diagnóstico y tratamiento de osteocondrosis. Vet México 42: 311:329.
7. Korkusuz P, Köse S, Yersal N, Önen S. 2018. Magnetic-based cell isolation technique for the selection of stem cells. In: Skin stem cells. Methods in molecular biology, New York: Humana press. p 153-163.

8. Koyama N, Okubo Y, Nakao K, Osawa K, Fujimura K, Bessho K. 2011. Pluripotency of mesenchymal cells derived from synovial fluid in patients with temporomandibular joint disorder. Life Sci 89: 741-747. doi: 10.1016/ j.lfs.2011.09.005

9. Murata D, Miyakoshi D, Hatazoe T, Miura N, Tokunaga S, Fujiki M, Nakayama K, Misumi K. 2014. Multipotency of equine mesenchymal stem cells derived from synovial fluid. Vet J 202: 53-61 . doi: 10.1016/j.tvj1.2014.07.029

10. Otsuki S, Grogan SP, Miyaki S, Kinoshita M, Asahara H, Lotz MK. 2010. Tissue neogenesis and STRO-1 expression in immature and mature articular cartilage. J Orthop Res 28: 96-102. doi: 10.1002/jor.20944

11. Prado AA, Favaron PO, da Silva LC, Baccarin RY, Miglino MA, Maria DA. 2015. Characterization of mesenchymal stem cells derived from the equine synovial fluid and membrane. BMC Vet Res 11:281. doi: 10.1186/s12917-015-0531-5

12. Psaltis PJ, Paton S, See F, Arthur A, Martin $S$, Itescu $S$, Worthley $S G$, et al. 2010. Enrichment for STRO-1 expression enhances the cardiovascular paracrine activity of human bone marrowderived mesenchymal cell populations. $J$ Cell Physiol 223: 530-540. doi: 10.1002/ jcp. 22081

13. Santos VH, Pfeifer JPH, de Souza JB, Milani BHG, de Oliveira RA, Assis MG, Deffune E, et al. 2018. Correction to: Culture of mesenchymal stem cells derived from equine synovial membrane in alginate hydrogel microcapsules. Stem Cell Res Ther 9: 259. doi: 10.1186/ s13287-018-0999-6 
14. Takeyasu M, Nozaki T, Daito M. 2006. No title differentiation of dental pulp stem cells into neural lineage. Pediatr Dent J 16: $154-162$.

15. Tondreau T, Lagneaux L, Dejeneffe M, Massy M, Mortier C, Delforge A, Bron D. 2004. Bone marrow-derived mesenchymal stem cells already express specific neural proteins before any differentiation. Differentiation 72: 319-326. doi: $10.1111 / \mathrm{j} .1432-0436.2004 .072-$ 07003. $\mathrm{x}$

16. Tsai CC, Su PF, Huang YF, Yew TL, Hung SC. 2012. Oct4 and nanog directly regulate Dnmt1 to maintain self-renewal and undifferentiated state in mesenchymal stem cells. Mol Cell 47: 169-182. doi: 10.1016/j.molcel.2012.06.020
17. Vinod E, Boopalan PRJVC, Sathishkumar S. 2018. Reserve or resident progenitors in cartilage? Comparative analysis of chondrocytes versus chondroprogenitors and their role in cartilage repair. Cartilage 9: 171-182. doi: 10.1177/ 1947603517736108

18. Xu J, Wang W, Kapila Y, Lotz J, Kapila S. 2009. Multiple differentiation capacity of STRO-1+/CD146+ PDL mesenchymal progenitor cells. Stem Cells Dev 18: 487-496. doi: 10.1089/ scd.2008.0113

19. Zayed M, Caniglia C, Misk N, Dhar MS. 2017. Donor-matched comparison of chondrogenic potential of equine bone marrow- and synovial fluid-derived mesenchymal stem cells: implications for cartilage tissue regeneration. Front Vet Sci 3: 121. doi: 10.3389/fvets.2016.0012 